\title{
Understanding training needs in eating disorders of graduating and new graduate dietitians in Australia: an online survey
}

\author{
Elyse Denman ${ }^{1 \dagger}$, Elizabeth Kumiko Parker ${ }^{2,3^{*}+}$ (D), Mellisa Anne Ashley ${ }^{2,4}$, Deanne Maree Harris ${ }^{5}$, Mark Halaki ${ }^{3}$, \\ Victoria Flood ${ }^{3,6}$ and Anita Stefoska-Needham ${ }^{1}$
}

\begin{abstract}
Background: Following recent reforms by the Australian Government to the Medicare Benefits Schedule, people living with a diagnosed eating disorder (ED) in Australia have greater access to dietetic services. However, new graduate dietitians anecdotally lack confidence to provide appropriate interventions to support patients with an ED. Therefore, this cross-sectional study aims to explore the perceived confidence, and educational and professional development needs of student dietitians and new graduate dietitians in the area of EDs.

Methods: An online survey with 17 questions was designed, consisting of a combination of discrete (yes/no) questions, free text, ordered scales and 5-point Likert scales. Student dietitians, and first- and second- year graduates $(n=1456$ ) were approached via email as potential participants, from the professional organisation Dietitians Australia member list. Survey data was analysed using descriptive statistics and odds ratios.

Results: In total, 150 surveys were completed, with a response rate of 10.3\%. Respondents reported a lack of confidence in managing patients with an ED and implementing ED treatment approaches (81 and 95\%, respectively). However, participants previously exposed to patients with an ED, such as anorexia nervosa, were 4.7 times $(95 \% \mathrm{Cl} 1.72,12.97)$ more likely to be confident compared to those not exposed to patients with an ED. The majority of respondents (37\%) stated they would seek assistance from other dietitians, and develop their skills via online webinars (27\%) and workshops (25\%).

Conclusions: This survey identified that final year dietetics students and new graduate dietitians perceive lower levels of confidence to practice in the area of EDs. The desire for further ED-specific training and education was reported.
\end{abstract}

Keywords: Eating disorders, Dietitian, Education and training

\section{Plain English summary}

Reforms by the Australian Government to the Medicare Benefits Schedule in 2019, have allowed greater access to dietetic services for people living with an eating disorder (ED). However, the confidence level of new

\footnotetext{
* Correspondence: Elizabeth.Parker@health.nsw.gov.au

${ }^{2}$ Department of Dietetics \& Nutrition, Westmead Hospital, Westmead, NSW 2145, Australia

${ }^{3}$ Sydney School of Health Sciences, Faculty of Medicine and Health, The University of Sydney, Sydney, NSW 2006, Australia

Full list of author information is available at the end of the article
}

graduate dietitians to treat patients with an ED has been reported as low. This study aimed to explore the perceived confidence, educational and professional development needs in the area of EDs, of students enrolled in their final year of an accredited nutrition and dietetics university program and dietitians who had graduated within the previous two-year period. Between 28th May 2019 and 25th June 2019, 1456 final year student and new graduate dietitians were invited to participate in an online survey, distributed by the professional organisation Dietitians Australia membership list. Of the 150

(C) The Author(s). 2021 Open Access This article is licensed under a Creative Commons Attribution 4.0 International License, which permits use, sharing, adaptation, distribution and reproduction in any medium or format, as long as you give appropriate credit to the original author(s) and the source, provide a link to the Creative Commons licence, and indicate if changes were made. The images or other third party material in this article are included in the article's Creative Commons licence, unless indicated otherwise in a credit line to the material. If material is not included in the article's Creative Commons licence and your intended use is not permitted by statutory regulation or exceeds the permitted use, you will need to obtain permission directly from the copyright holder. To view a copy of this licence, visit http://creativecommons.org/licenses/by/4.0/ The Creative Commons Public Domain Dedication waiver (http://creativecommons.org/publicdomain/zero/1.0/) applies to the data made available in this article, unless otherwise stated in a credit line to the data. 
surveys completed, $81 \%$ of respondents reported a lack of confidence in managing patients with an ED and 95\% reported a lack of confidence in using various ED treatment approaches. The desire for further eating disorder specific training and education was reported.

\section{Background}

Eating Disorders (EDs) are psychiatric illnesses which are typically characterised by persistent disordered eating behaviours and/or compensatory behaviours to control body weight or shape [1]. EDs, including anorexia nervosa, bulimia nervosa, binge eating disorder and avoidant/restrictive food intake disorder (ARFID), are associated with severe psychological distress and, may also lead to complex long term medical comorbidities such as infertility, cardiovascular symptoms, digestive disorders, fatigue and pain [1-4]. Anorexia nervosa in particular, is the most fatal of any psychiatric disorder [5].

In Australia, prevalence data indicates approximately $16 \%$ of adults and $8-15 \%$ of adolescents are affected with an ED [6, 7]. With early diagnosis and appropriate interventions, including preventative health and wellbeing interventions, the incidence, prevalence and severity of EDs may be reduced [8, 9]. A recovery orientated approach to treatment is recommended, with coordinated continuous, multidisciplinary care from skilled professionals, including dietitians [8].

Accessibility to treatment has remained a concern for this patient group. It has been reported that $20-43 \%$ of people with EDs seek treatment for their ED from a healthcare provider [10-12], and health funding for ED management has been limited, with only 37 dedicated adult hospital beds available across Australia for EDs in 2016 [13]. For those seeking outpatient treatment, previously a maximum of 10 sessions for psychological services from a range of eligible treating health professionals and 5 dietetic consultations per year were funded by the Australian Government under the Medicare Benefits Schedule (MBS). This was deemed to be insufficient to treat patients with an ED to full recovery and resulted in large out-of-pocket treatment costs for those individuals [14]. In recognition of this shortfall in services, the New South Wales Health Department released a state-wide service plan for people with EDs in 2013 to implement strategies for improved primary and community based interventions, as well as local hospital interventions [15]. Additional reforms by the Australian Government to the MBS were introduced in November 2019, offering eligible patients diagnosed with an ED up to 40 sessions for psychological services from a range of eligible treating health professionals, and 20 dietetic sessions per year [16]. While the rate of uptake of the scheme is currently unknown, these reforms have the potential to reduce hospitalisation costs, increase recovery rates and improve the overall quality of life for many people.

These changes to the MBS for the treatment of EDs represent potential growth in employment opportunities for the dietetics profession, in particular for new graduates to work in private practice compared to more traditional hospital-based settings [17]. To this end, new graduate dietitians may be more likely to encounter both an undiagnosed patient with an ED or a patient with a diagnosed ED in private practice clinics.

Practising safely and within a defined scope of practice is essential for the delivery of safe care to ED patients, across all disciplines. From a dietetic perspective, an understanding of how to work within one's scope of practice can be facilitated by adherence to the Dietitians Association (DA) Code of Professional Conduct [18] and the Ethical Practice Statement [19], and guidance from entry level dietetic competencies (National Competency Standards for Dietitians - NCSD) [20], which focus on general professional attributes (knowledge, attitudes and skills). Dietitians practising in the ED area may also refer to ED-specific national practice standards developed by the National Eating Disorder Collaboration (NEDC) for health care providers [21]. The Australia and New Zealand Academy for Eating Disorders (ANZAED) have recently published ED treatment principles and general clinical practice and training standards for mental health professionals and dietitians [22]. The ANZAED have also published practice and training standards specific for dietitians providing ED treatment, to ensure the safe and effective treatment of individuals with an ED [23]. Furthermore, in response to the lack of clinical practice guidelines for dietetic treatment of EDs, McMaster et al. (2020) [24] developed consensus-based guidelines for the outpatient setting.

Inadequate training in EDs has been identified as a workforce challenge across various health professionals, including dietitians [25-30]. Additionally, there are concerns that health professionals with limited clinical experience especially in the area of ED management principles, may unintentionally cause harm or even delay recovery [31]. Maguire et al. (2019) [32] report that practitioners' poor self-belief to practice competently may create stigmatised attitudes towards patients with EDs and could impede the clinical care process. This in turn may result in an absence of or untimely referrals to specialist treatment services, such as dietetics [32]. Whether dietetic students and new graduate dietitians feel the same is currently unknown due to the paucity of literature in this area.

Therefore, the present study aims to explore the perceived confidence levels of student and new graduate dietitians to treat patients with an ED, their confidence in working with various ED treatment approaches, and 
their professional development and training needs. These findings may be used to inform the development of tertiary and post graduate training opportunities that enhance dietitians' confidence to practice in the ED field, and in the longer-term, assist in achieving better outcomes for people with EDs through the provision of improved dietetic care.

\section{Methods}

This cross sectional study used an exploratory research approach, utilising a purpose built online survey. Participants were recruited from the professional organisation DA membership list following their expression of interest to participate. Inclusion criteria were students enrolled in their final year of an Australian nutrition and dietetics university program and dietitians who had graduated within the previous two-year period. Engaging the DA membership list increased the likelihood of representativeness, as DA is the peak body for dietetic and nutrition professionals in Australia [33]. Participation in the study was anonymous and voluntary, with consent implied by online survey completion. Ethical approval was received from The University of Sydney Human Research Ethics Committee (Project No. 2019/078). This study was prepared based on strengthening the reporting of observational studies in epidemiology (STROBE) statement for cross-sectional studies [34].

The survey consisted of 17 questions, including a combination of discrete (yes/no) questions, free text, ordered scales and 5-point Likert scales. Participants were asked about their perceived confidence to treat patients with an ED and the use of different treatment modalities, seeking advice and their preferred methods for further training and education. The treatment approaches explored included dietary counselling $[35,36]$, mindful eating [37, 38], Health at Every Size (HAES) [39, 40], intuitive eating $[41,42]$, motivational interviewing [35, $36,43]$, developing meal plans for weight restoration [35], and the Real Food Guide [44]. While HAES is not a recognised treatment approach specifically for ED treatment, it was included in the survey as the HAES weight inclusive approach to health has emerged in the ED field, in particular for individuals with binge eating disorder [40]. Face validity of the survey content was addressed in consultation with the professional organisation DA and a group of dietetic leaders in EDs, who also provided insight into commonly used treatment approaches used in dietetic practice for individuals with EDs. Prior to dissemination, the survey was piloted online with 5 independent dietitians for internal consistency and face validity. The survey was open for 4 weeks from the 28th May 2019.

Data collected was analysed in Microsoft Excel (2013). Descriptive statistics were generated for all reported measures, summarised in counts and percentages. The 5-point-Likert scale responses were dichotomised into binary responses such as 'Agree' vs 'Not agree' to show clear trends in the data. Specifically, 'Strongly agree' and 'Agree' responses were grouped as 'Agree'. 'Strongly disagree', 'Disagree' and 'Neither agree nor disagree' were grouped as 'Not Agree'. 'Neither agree nor disagree' was counted as 'Not agree' based on the assumption that those people were less likely to feel confident in a specific area. For some questions, the mean percentage of responses was calculated. In order to calculate odds of association between exposure and confidence, responses were cross-tabulated between those who had encountered a patient with an ED and those who had not. Responses were dichotomised; whereby, disagreement with the statement in all settings was counted as 'not confident', while agreement in at least one setting was counted as 'confident'. Missing data was treated as follows; a participant with non-responses for a specific question was included in the study; however, the nonresponses were accounted for and not included in the analysis of that individual question. As a result, the sample size varied for each question.

\section{Results}

In total, 150 out of 1456 people participated in the study, yielding a $10.3 \%$ response rate. Participants comprised of primarily recent graduates $(77 \%)$ and a smaller proportion of final year students (21\%). Characteristics of participants, including their previous encounters with a patient with an ED, in either an inpatient or outpatient setting, are shown in Table 1.

A cross-tabulation of variables (ED type and treatment approaches) as a function of the relevant outcomes (perceived confidence and training needs) is shown in Table 2. Most participants $(81 \% \pm 3 \%)$ reported lacking confidence in treating patients with an ED, with $96 \% \pm$ $1 \%$ of participants reporting the need for further education and training (Table 2).

The most preferred methods to complete further training in the management of EDs were online webinars $(27 \%)$, followed by workshops (25\%); online courses (19\%); clinical supervision (15\%); site visits to ED services (5\%); DA Eating Disorder Interest Group (dietitians who are members of the professional organisation DA, who wish to network with other members in the area of EDs) [45] resources (4\%); other/ unspecified (3\%); and Practice-based Evidence in Nutrition (innovative knowledge translation tool developed by Dietitians of Canada) [46] (2\%).

Participants who had previously encountered a patient with an ED were more likely to be confident in providing dietetic services in the area of EDs (Table 3). 
Table 1 Characteristics of survey participants

\begin{tabular}{ll}
\hline & $\begin{array}{l}\text { Responses } \\
\mathbf{n}(\%)\end{array}$ \\
\hline State/territory completed studies in & \\
New South Wales & $46(31)$ \\
Victoria & $35(23)$ \\
Australian Capital Territory & $12(8)$ \\
Queensland & $38(25)$ \\
South Australia & $1(1)$ \\
Western Australia & $11(7)$ \\
Tasmania & $6(4)$ \\
Location not identified & $1(1)$ \\
Academic Status & \\
1st year graduate & $60(40)$ \\
2nd year graduate & $56(37)$ \\
Enrolled in final year of Nutrition \& & $32(21)$ \\
Dietetics university program & \\
Academic status not identified & $2(1)$ \\
Encountered a patient with an ED to date? & \\
Yes & $107(71)$ \\
No & $43(29)$ \\
TOTAL & $150(100)$ \\
\hline
\end{tabular}

On the topic of clinical support, $62 \%(n=93)$ of participants reported they felt confident knowing where to seek assistance (Table 4). Key sources of support were identified as "other Dietitians" (including clinical supervisor/mentor, ED specialist dietitian, senior dietitian/manager) and evidence based guidelines.

\section{Discussion}

The present study provides insight into the educational and professional development needs of student dietitians and new graduate dietitians in the area of EDs, and reports on their perceived confidence to practice professionally in treating EDs. Currently, dietitians may be more likely to encounter a patient with an ED within the community setting, with considerable growth in the number of new graduate dietitians' in Australia working in private practice $(24 \%)$ compared to more traditional settings, such as public hospitals (23\%) [17]. The introduction of government incentives in Australia through the MBS to support ED service provision in the community in 2019 [16], may further drive this trend in the future. Practically this means that dietitians may be more likely to encounter both diagnosed and undiagnosed ED patients in private practice clinics [47], with many patients expected to seek treatment of symptoms even in the absence of a formal ED diagnosis. Hence, the traditional views that ED training should be reserved for experienced or specialist dietitians seems redundant in the current context [47].

Our survey findings indicate final year student and new graduate dietitians perceive a lack of confidence to practice confidently in the area of EDs and they identify a number of training gaps. This result was expected given that experienced dietitians also report a lack of professional confidence in working with clients

Table 2 Perceived confidence and need for further training, in treating patients with an ED and engagement in treatment approaches

\begin{tabular}{|c|c|c|c|c|}
\hline & \multicolumn{2}{|c|}{ Reported Confidence } & \multicolumn{2}{|c|}{$\begin{array}{l}\text { Requires } \\
\text { Further Training }\end{array}$} \\
\hline & Confident \% & Not Confident $\%$ & Yes $\%$ & No $\%$ \\
\hline \multicolumn{5}{|l|}{ Diagnosis } \\
\hline Anorexia Nervosa & 16 & 84 & 95 & 5 \\
\hline Bulimia Nervosa & 16 & 84 & 95 & 5 \\
\hline Binge Eating Disorder & 23 & 77 & 95 & 5 \\
\hline ARFID & 19 & 81 & 97 & 3 \\
\hline Any ED & 19 & 81 & 96 & 4 \\
\hline \multicolumn{5}{|l|}{ Using Treatment Approaches } \\
\hline Dietary Counselling & 44 & 56 & 92 & 8 \\
\hline Mindful Eating & 35 & 65 & 93 & 7 \\
\hline Health at Every Size & 29 & 71 & 89 & 11 \\
\hline Intuitive Eating & 39 & 61 & 91 & 9 \\
\hline Motivational Interviewing & 41 & 59 & 95 & 5 \\
\hline Developing Meal Plans for weight restoration & 57 & 43 & 85 & 15 \\
\hline The Real Food Guide & 23 & 77 & 94 & 6 \\
\hline
\end{tabular}

ED, eating disorder; ARFID, avoidant restrictive food intake disorder 
Table 3 Relationship between exposure to a patient with an ED and confidence to provide dietetic services

\begin{tabular}{|c|c|c|c|c|c|}
\hline \multirow[b]{2}{*}{ Confidence to Treat } & & \multicolumn{4}{|c|}{ Encountered a patient with an ED } \\
\hline & & Yes & No & OR & $95 \% \mathrm{Cl}$ \\
\hline \multirow[t]{2}{*}{ Anorexia Nervosa } & Confident & 41 & 5 & 4.7 & $1.72,12.97$ \\
\hline & Not Confident & 66 & 38 & & \\
\hline \multirow[t]{2}{*}{ Bulimia Nervosa } & Confident & 35 & 4 & 4.7 & $1.57,14.32$ \\
\hline & Not Confident & 72 & 39 & & \\
\hline \multirow[t]{2}{*}{ Binge Eating Disorder } & Confident & 43 & 6 & 4.1 & $1.61,10.66$ \\
\hline & Not Confident & 64 & 37 & & \\
\hline \multirow[t]{2}{*}{ ARFID } & Confident & 34 & 5 & 3.5 & $1.28,9.79$ \\
\hline & Not Confident & 73 & 38 & & \\
\hline
\end{tabular}

ARFID, avoidant restrictive food intake disorder

experiencing mental health issues [48]. Future research examining the ways new graduate dietitians plan to upskill in this clinical area would be valuable, and importantly, whether these activities are likely to positively influence their practice should be examined. Growing professional confidence when working within EDs is paramount, for not only the health care professional, but their patients. Greater recognition of symptoms, referral and treatment, as well as a reduction in stigmatised beliefs, may improve with further training [32].

Encounters with patients with EDs vary between health professionals and a lack of exposure to these patients may affect confidence to practice. Physicians typically report minimal encounters [49]. In contrast, findings of the present study suggest that responding new graduate dietitians and final year students on clinical placement, had a reasonably high number of ED encounters ( $71 \%$ of respondents), but due to low response rate the generalisability of the findings are limited. While this higher proportion may be explained by self-selection bias (that is, dietitians and final year students with an interest in EDs who agreed to participate in the survey),

Table 4 Main sources of assistance that dietitians use in managing patients with an ED

\begin{tabular}{ll}
\hline Source for Assistance & Responses $\mathbf{n}(\%)$ \\
\hline Other Dietitians & $55(37)$ \\
Evidence Based Guidelines & $24(16)$ \\
ED Associations & $10(7)$ \\
DA/Interest Group/Resources & $10(7)$ \\
MDT Staff & $10(7)$ \\
Other Online Resources/Books & $8(5)$ \\
ED Services & $7(5)$ \\
Webinar/Workshop & $3(2)$ \\
Total No. Responses & $127(85)$ \\
\hline
\end{tabular}

ED, Eating Disorder; DA, Dietitians Australia; MDT, Multidisciplinary Team dietitians may also be more likely than physicians to encounter patients with an ED as food is a core aspect of an ED.

Clinical placement experiences are integral to workforce preparation, as practical experiences have been shown to influence confidence levels and they have the potential to shape career path intentions [50]. Despite this, current Australian accredited dietetics programs have limited ED placement opportunities, influenced largely by placement partner collaboration agreements that have a small number of ED offerings, and geographical allocation of students $[29,51]$. This appears to also be a barrier in other countries and across different disciplines such as medicine, where from 637 residency programs in the USA, only 42 formal ED training rotations were offered [27]. This situation is unlikely to change, hence alternatives that do not require more clinical placement capacity are important to consider. For example, student participation in ED-specific simulations or objective structured clinical exams may offer greater pragmatic training opportunities, without increasing the burden on placements. These could be developed through collaboration between universities and dietitian advocacy groups, such as the DA Eating Disorder Interest Group. Once fully qualified, continual professional development becomes integral to the ongoing learning development of dietitians, in order to maintain and enhance the knowledge and skills they need to deliver a professional standard of service. Mentorship and clinical supervision were identified by respondents in the present study as important professional development engagements.

Evidence based guidelines, including treatment manuals [52, 53], are an important part of navigating uncertainty in clinical practice. Prior to the recent publication of the ANZAED practice and training standards for dietitians [23], and the work of McMasters et al. (2020) on the role of the dietitian and nutrition in evidence basedtreatment $[24,53,54]$, there was a lack of guidance for 
dietetic practice in EDs. This may have contributed to dietitians' perceived lack of confidence in ED treatment. For example, The Royal Australian and New Zealand College of Psychiatrists clinical practice guidelines [2], refer to dietitians' involvement but they lack specific recommendations for implementation in daily practice. In the UK, the National Institute for Health and Care Excellence Guidelines [55] do not specify that nutrition psychoeducation and management of refeeding syndrome should be completed by a dietitian, while the American Psychological Association [56] stipulates that dietitians may only provide structured meal plans to ensure nutritional adequacy.

Although dietitians recognise the importance of facilitating behaviour change in managing patients with EDs, often they lack knowledge of specific behaviour change methods to effectively support and care for people with EDs [57]. Our survey findings indicated more than half of final year student and new graduate dietitians lacked confidence in applying treatment approaches such as Motivational Interviewing. Insights into mental health concerns and communication skills are fundamental to dietetic practice generally, and specifically in relation to EDs, an understanding of cognitive behavioural therapy principles is required [36, 58]. Acquiring these skills could lead to improved confidence in identification and initiation of conversations with a patient, promoting timely specialised treatment [47] and facilitation of change in eating behaviours [29].

Some limitations were encountered during this research, notably self-selection bias of participants who may have had a particular interest in EDs and greater exposure to them, potentially resulting in divergent perceptions to the broader dietetics workforce. The response rate was low and some states where participants completed their studies were over represented, which limits the generalisability of the findings to the broader dietetic community. Also, incomplete survey responses were not further explored. The low response rate suggests that relying solely on a professional organisation representing dietitians in Australia for survey distribution did not capture a high level of interest in participation. Approaching and engaging specific ED organisations and advocacy groups for a more targeted approach in survey distribution, may have resulted in a higher response rate and should be considered in future studies.

Further research evaluating current course curricula through perspectives of course convenors would be valuable. Exploring perspectives of dietitians with longer term and more diverse practice histories, is also recommended to provide deeper insights into issues highlighted in this study. A better understanding of workforce preparation for graduate dietitians specifically is also warranted in future studies, as is knowledge of current professional settings and private practice experiences. This collective knowledge would assist in identifying potential barriers and enablers in meeting the growing dietetic demands for ED services [59].

\section{Conclusions}

In conclusion, findings of this survey confirm there is an overall lack of confidence in final year student and new graduate dietitians to work with patients with an ED. A need for further ED-specific education and professional development was highlighted. Widely accessible tertiary and post graduate training opportunities in counselling skills (e.g. motivational interviewing), as well as participating in structured clinical supervision may improve practitioner confidence and improve patient outcomes.

\section{Abbreviations}

ED: Eating Disorder; ARFID: Avoidant/restrictive food intake disorder; MBS: Medicare Benefits Schedule; NCSD: National Competency Standards for Dietitians; NEDC: National Eating Disorder Collaboration; DA: Dietitians Australia; MDT: Multidisciplinary Team; ANZAED: Australian and New Zealand Academy for Eating Disorders

\section{Acknowledgements \\ The authors would like to acknowledge Dietitians Australia for the distribution of the online survey to participants.}

\section{Authors' contributions \\ $E P, M A$ and DH were involved in the conception and development of the study design. EP, MA and DH were involved in the development of the purpose built questionnaire, with contributions from VF. ED was involved in data collection and analysis, with contributions from MH, VF and ASN. ED drafted the manuscript, with contributions from ASN and EP. All authors read and critically revised the manuscript and approve the final manuscript.}

\section{Funding}

No sources of funding to declare.

\section{Availability of data and materials}

The datasets used and/or analysed during the current study are available from the corresponding author on reasonable request.

\section{Ethics approval and consent to participate}

This study received ethical approval from The University of Sydney Human Research Ethics Committee (Project No. 2019/078).

\section{Consent for publication}

Not applicable.

\section{Competing interests}

The authors declare that they have no competing interests.

\section{Author details}

${ }^{1}$ SMART Foods Centre, Illawarra Health and Medical Research Institute, School of Medicine, Faculty of Science, Medicine and Health, University of Wollongong, Wollongong, NSW 2522, Australia. ${ }^{2}$ Department of Dietetics \& Nutrition, Westmead Hospital, Westmead, NSW 2145, Australia. ${ }^{3}$ Sydney School of Health Sciences, Faculty of Medicine and Health, The University of Sydney, Sydney, NSW 2006, Australia. ${ }^{4}$ Adult Eating Disorder Service, Western Sydney Local Health District, Sydney, NSW 2145, Australia. ${ }^{5}$ Department of Dietetics \& Nutrition, Tamworth Rural Referral Hospital, Tamworth, NSW 2340, Australia. ${ }^{6}$ Western Sydney Local Health District, Sydney, NSW 2145, Australia. 


\section{Received: 27 October 2020 Accepted: 9 February 2021}

\section{Published online: 18 February 2021}

\section{References}

1. Treasure J, Claudino AM, Zucker N. Eating disorders. Lancet. 2010;375(9714): 583-93.

2. Hay P, Chinn D, Forbes D, Madden S, Newton R, Sugenor L, Touyz S, Ward W. Royal Australian and new Zealand College of Psychiatrists clinical practice guidelines for the treatment of eating disorders. Australian \& New Zealand Journal of Psychiatry. 2014;48(11):977-1008.

3. Mitchell JE. Medical comorbidity and medical complications associated with binge-eating disorder. Int J Eat Disord. 2016;49:319-23.

4. Aulinas A, Marengi DA, Galbiati F, Asanza E, Slattery M, Mancuso CJ, Wons O, Micali N, Bern E, Eddy KT, Thomas JJ, Misra M, Lawson EA. Medical comorbidities and endocrine dysfunction on low-weightfemales with avoidant/restrictive food intake disorder compared to anorexia nervosa and healthy controls. Int J Eat Disord. 2020;53:631-6.

5. Arcelus J. Mortality rates in patients with anorexia nervosa and other eating disorders. Arch Gen Psychiatry. 2011;68(7):724-31.

6. Hay P, Girosi F, Mond J. Prevalence and sociodemographic correlates of DSM-5 eating disorders in the Australian population. J Eat Disord. 2015;3:19.

7. Allen KL, Byrne SM, Oddy WH, Crosby RD. DSM-IV-TR and DSM-5 eating disorder in adolescents: prevalence, stability and psychosocial correlates in a population-based sample of male and female adolescents. J Abnorm Psychol. 2013;122:720-32.

8. National Eating Disorders Collaboration. An Integrated Response to Complexity: National Eating Disorders Framework. Report to the Australian Government Department of Health and Ageing. [Internet] NSW; NEDC; March 2012 [cited 2019 March 20]. Available from: https://www.nedc.com.a u/assets/NEDC-Publications/National-Framework-An-integrated-Response-toComplexity-2012-Final.pdf

9. Campbell K, Peebles R. Eating disorders in children and adolescents: state of the art review. Pediatrics. 2014;134:582-92

10. Hudson Jl, Hiripi E, Pope HG Jr, Kessler RC. The prevalence and correlates of eating disorders in the National Comorbidity Survey Replication. Biol Psychiatry. 2007;61:348-58.

11. Hart LM, Granillo MT, Jorm AF, Paxton SJ. Unmet need for treatment in the eating disorders: a systematic review of eating disorder specific treatment seeking among community cases. Clin Psychol Rev. 2011;31:727-35.

12. Forrest LN, Smith AR, Swanson SA. Characteristics of seeking treatment among U.S. adolescents with eating disorders. Int J Eat Disord. 2017;50: 826-33.

13. Butterfly Foundation (AU). Health System for all Australians, not just some [Internet]. 2016, [cited 2019 Oct 9]. Available from: https:// thebutterflyfoundation.org.au/about-us/media-centre/media-releases/healthsystem-for-all-australians-not-just-some/

14. Dietitians Association of Australia. Eating Disorders and the Medicare Benefits Schedule (MBS) Review [Internet]. Canberra (ACT); DAA; 2018 [cited 2019 Feb 2] Available from https://daa.asn.au/wp-content/uploads/2018/12/ DAA_Eating-Disorders-MBS-Review_Oct-2018.pdf

15. NSW Ministry of Health. NSW Service Plan for People with Eating Disorders 2013-2018. [Internet]. North Sydney (NSW); NSW Health; 2013 [cited 2020 April 29] Available from https://www.health.nsw.gov.au/mentalhealth/ resources/Publications/service-plan-eating-disorders-2013-2018.pdf

16. Australian Government Department of Health. Medicare Benefits Schedule: Eating Disorders - Quick Reference Guide; 29/10/2019 [cited 2020 May 23] Available from: http://www.mbsonline.gov.au/internet/mbsonline/ publishing.nsf/Content/773AA9AA09E7CA00CA2584840080F113/\$File/Ea ting\%20Disorders\%200uick\%20Reference\%20Guide\%20290ct2019.pdf

17. Collins J. Generational change in nutrition and dietetics: the millennial dietitian. Nutrition \& Dietetics. 2019;76:369-72.

18. Dietitians Association of Australia. Code of Professional Conduct for members with Australian recognised dietetic qualifications, and nonmembers with APS status. March 2013 [cited 2020 October 7]. Available from: https://dietitiansaustralia.org.au/wp-content/uploads/2017/01/2013Code-of-Professional-Conduct-member-and-APD.pdf

19. Dietitians Association of Australia. Statement of Ethical Practice for members with Australian recognised dietetic qualifications, and non-members with APD status. December 2014 [cited 2020 October 7]. Available from: https:// dietitiansaustralia.org.au/wp-content/uploads/2019/02/2014-Statement-ofEthical-Practice-Member-and-APD.pdf
20. Dietitians Association of Australia. National Competency Standards for Dietitians in Australia. 2015 [cited 2020 October 7]. Available from: https:// dietitiansaustralia.org.au/wp-content/uploads/2020/08/NCS-Dietitians-Austra lia-1.0.pdf

21. National Eating Disorders Collaboration. National Practice Standards for eating disorders [internet] NSW; NEDC; January 2020 [cited 2020 April 19]. Available from: https://www.nedc.com.au/assets/NEDC-Resources/nationalpractice-standards-for-eating-disorders.pdf

22. Heruc G, Hurst K, Casey A, Fleming K, Freeman J, Fursland A, Hart S, Jeffrey S, Knight R, Roberton M, Roberts M, Shelton B, Stiles G, Sutherland F, Thornton C, Wallis A, Wade T. ANZAED eating disorder treatment principles and general clinical practice and training standards. J Eat Disord. 2020;8:63.

23. Heruc G, Hart S, Stiles G, Fleming K, Casey A, Sutherland F, Jeffrey S, Roberton M, Hurst K. ANZAED practice and training standards for dietitians providing eating disorder treatment. J Eat Disord. 2020;8:77.

24. McMaster CM, Wade T, Franklin J, Hart S. Development of consensus-based guidelines for outpatient dietetic treatment of eating disorders: a Delphi study. Int J Eat Disord. 2020;53:1480-95.

25. Linville D, Aoyama T, Knoble N, Gau J. The effectiveness of a brief eating disorder training programme in medical settings. J Res Nurs. 2012;18(6):544-58.

26. Gurney V, Halmi K. Developing an eating disorder curriculum for primary care providers. Eat Disord. 2001;9(2):97-107.

27. Mahr F, Farahmand P, Bixler E, Domen R, Moser E, Nadeem T, et al. A national survey of eating disorder training. Int J Eat Disord. 2014;48:443-5.

28. Williams $M$, Leichner $P$. More training needed in eating disorders: a time cohort comparison study of Canadian psychiatry residents. Eat Disord. 2006; 14:323-34.

29. Trammell E, Reed D, Boylan M. Education and practice gaps of registered dietitian nutritionists working with clients with eating disorders. Top Clin Nutr. 2016;31(1):73-85

30. Dowding K, Ash S, Shakespeare-Finch J. Using critical incident interviews to identify the mental health knowledge, skills and attitudes of entry-level dietitians. Nutrition \& Dietetics. 2011;68(4):297-304.

31. Garner DM. latrogenesis in anorexia nervosa and bulimia nervosa. Int J Eat Disord. 1985:4:701-26.

32. Maguire S, Li A, Cunich M \& Maloney D. Evaluating the effectiveness of an evidence-based online training program for health professionals in eating disorders. Journal of Eating Disorders. 2019; 7(1).

33. Dietitians Australia (2020). Dietitians Australia. Available at: http://www. dietitiansaustralia.org.au ().

34. von Elm E, Altman DG, Egger M, et al. Strengthening the reporting of observational studies in epidemiology (STROBE) statement: guidelines for reporting observational studies. BMJ. 2007;335:806-8.

35. Wakefield A, Williams H. Practice recommendations for the nutritional management of anorexia nervosa in adults. [Internet] 2009. [cited 2020 December 24]. Available from: https://insideoutinstitute.org.au/assets/pra ctice $\% 20$ recommendations\%20for\%20the\%20nutritional\%20management\%2 0of\%20anorexia\%20nervosa\%20in\%20adults.pdf

36. Ozier AD, Henry BW. Position of the American dietetic association: nutrition intervention in the treatment of eating disorders. J Am Diet Assoc. 2011; 111:1236-41.

37. Warren JM, Smith N, Ashwell M. A structured literature review on the role of mindfulness, mindful eating and intuitive eating in changing eating behaviours: effectiveness and associated potential mechanisms. Nutr Res Rev. 2017;30:272-83.

38. Hepworth NS. A mindful eating group as an adjunct to individual treatment for eating disorders: a pilot study. Eat Disord. 2010;19:6-16.

39. HAES Australia Steering Committee (2017). HAES Australia Position Statement: Weight Neutral Care. [cited 2020 December 24]. Available from: https://haesaustralia.org.au/resources/Documents/haes_australia_position_ statement_for_weight_neutral_care.pdf

40. Bacon L, Aphramor L. Weight science: evaluating the evidence for a paradigm shift. Nutr J. 2011;10:9.

41. Richards PS, Crowton S, Berrett ME, Smith MH, Passmore K. Can patients with eating disorders learn to eat intuitively? A 2-year pilot study. Eat Disord. 2017;25:99-113.

42. Burnette CB, Mazzeo SE. An uncontrolled pilot feasibility trial of an intuitive eating intervention for college women with disordered eating delivered through group and guided self-help modalities. Int J Eat Disord. 2020;53: 1405-17. 
43. Macdonald P, Hibbs R, Corfield F, Treasure J. The use of motivationa interviewing in eating disorders: a systematic review. Psychiatry Res. 2012; 200:1-11.

44. Hart S, Marnane C, McMaster C, Thomas A. Development of the "recovery from eating disorders for life" food guide (REAL food guide) - a food pyramid for adults with an eating disorder. J Eat Disord. 2018;6:6.

45. Dietitians Association of Australia (2016). DAA Interest Group and Discussion Group Manual. [cited 2020 December 24]. Available from: https://dietitiansa ustralia.org.au/wp-content/uploads/2016/09//G-DG-Manual-2016.pdf

46. Practice-based Evidence in Nutrition (2020). PEN The Global Resource for Nutrition Practice. Available at: https://www.pennutrition.com/index.aspx ().

47. Gulliksen K, Nordbø R, Espeset E, Skårderud F, Holte A. The process of helpseeking in anorexia nervosa: patients' perspective of first contact with health services. Eat Disord. 2014;23:206-22.

48. Ozier A, Henry B. Preliminary report on dietitians' views and confidence related to nutrition Care for Eating Disorders. ICAN. 2010;2(2):106-11.

49. Davidson, A., Braham, S., Dasey, L., \& Reidlinger, D. Physicians' perspectives on the treatment of patients with eating disorders in the acute setting. Journal of Eating Disorders. 2019; 7(1).

50. McCall L, Palermo C, Wray N. Placements and their influence on Australian nutrition and dietetics students. Focus on Health Professional Education. 2009:11:14-21

51. Brownlow R, Maguire S, O'Dell A, Dias-da-Costa C, Touyz S, Russell J. Evaluation of an online training program in eating disorders for health professionals in Australia. J Eat Disord. 2015;3:37.

52. Lock J, Le Grange D, Agras W.S., C Dare. Treatment manual for anorexia nervosa: A family based approach. 2001. New York: Guildford publications, Inc.

53. McMaster CM, Wade T, Franklin J, Hart S. A review of treatment manuals for adults with an eating disorder: nutrition content and consistency with current dietetic evidence. Eat Weight Disord 2020. https://doi.org/https:// doi.org/10.1007/s40519-020-00850-6.

54. McMaster CM, Wade T, Basten C, Franklin J, Ross J, Hart S. Rationale and development of a manualised dietetic intervention for adults undergoing psychological treatment for an eating disorder. Eat Weight Disord 2020. http://doi.org/https://doi.org/10.1007/s40519-020-00955-y.

55. National Institute for Health and Care Excellence. NICE Guidelines, Eating Disorders: Recognition and Treatment [Internet]. NICE; 2017. [cited 2019 Oct 7] Available from: https://www.nice.org.uk/guidance/ng69

56. Yager J, Devlin M, Halmi K, Herzog D, Mitchell J, Powers P, et al. Guideline watch (august 2012): practice guideline for the treatment of patients with eating disorders, 3rd edition. FOCUS. 2014;12:416-31.

57. Rapoport L, Perry K. Do dietitians feel that they have had adequate training in behaviour change methods? J Hum Nutr Diet. 2000;13:287-98.

58. Dietitians Association of Australia. Eating Disorder Role Statement: Role statement for accredited practising dietitians practising in the area of eating disorders. Canberra (ACT): DAA; 2017. [cited 2019, Feb 2]. Available from: https://dietitiansaustralia.org.au/wp-content/uploads/2015/05/EatingDisorders-Role-Statement-1.pdf

59. Morgan K, Kelly J, Campbell K, Hughes R, Reidlinger D. Dietetics workforce preparation and preparedness in Australia: a systematic mapping review to inform future dietetics education research. Nutrition \& Dietetics. 2018;76(1): 47-56.

\section{Publisher's Note}

Springer Nature remains neutral with regard to jurisdictional claims in published maps and institutional affiliations.

Ready to submit your research? Choose BMC and benefit from:
- fast, convenient online submission
- thorough peer review by experienced researchers in your field
- rapid publication on acceptance
- support for research data, including large and complex data types
- gold Open Access which fosters wider collaboration and increased citations
- maximum visibility for your research: over 100M website views per year
At BMC, research is always in progress.
Learn more biomedcentral.com/submissions

